\title{
Reversal of ventricular fibrillation with esmolol in an anaesthetized cat
}

Meira, Carolina ; Glaus, Tony M ; Ringer, Simone K

DOI: https://doi.org/10.1016/j.vaa.2018.03.014

Posted at the Zurich Open Repository and Archive, University of Zurich ZORA URL: https://doi.org/10.5167/uzh-153255

Journal Article

Accepted Version

Originally published at:

Meira, Carolina; Glaus, Tony M; Ringer, Simone K (2018). Reversal of ventricular fibrillation with esmolol in an anaesthetized cat. Veterinary Anaesthesia and Analgesia, 45(5):713-714.

DOI: https://doi.org/10.1016/j.vaa.2018.03.014 


\section{Reversal of ventricular fibrillation with esmolol in an anaesthetized cat}

Cardiac arrhythmias are common during interventional cardiac procedures. Ventricular fibrillation (VF) is a life-threatening arrhythmia that can culminate in death. The purpose of this letter is to describe cardioversion from VF using esmolol.

A 6 month old male intact Domestic Shorthair cat, weighing $3 \mathrm{~kg}$ presented with lethargy and dyspnoea. Pericardial, pleural and abdominal effusions were identified on ultrasound. There was marked left ventricular and atrial volume overload and moderate right ventricle (RV) concentric hypertrophy. A left to right patent ductus arteriosus (PDA) was visualized, but the aortic to pulmonary artery (PA) peak pressure gradient in systole was only approximately $30 \mathrm{mmHg}$ as measured with Doppler echocardiography. This low gradient, together with RV concentric hypertrophy, indicated pulmonary hypertension $(\mathrm{PH})$ secondary to $\mathrm{PA}$ remodelling from overperfusion.

The cat was stabilized, the effusions were drained, and treatment was started with furosemide (3 mg kg ${ }^{-1}$ am and $1.5 \mathrm{mg} \mathrm{kg}^{-1} \mathrm{pm}$; Dimazon; MSD, Switzerland) and benazepril $\left(0.25 \mathrm{mg} \mathrm{kg}^{-1}\right.$ once a day; Fortekor; Novartis, Switzerland). To confirm the diagnosis and to specifically quantify $\mathrm{PH}$ before duct occlusion (and to monitor RV pressure during surgical occlusion), the cat underwent general anaesthesia for angiography and RV pressure measurement followed by surgery. The cat was preoxygenated by mask and premedicated intravenously (IV) with fentanyl ( $5 \mathrm{mcg} \mathrm{kg}^{-1}$; Fentanyl Sintetica; Sintetica, Switzerland), and midazolam $\left(0.1 \mathrm{mg} \mathrm{kg}^{-1}\right.$; Dormicum; Roche, Switzerland), under electrocardiographic (ECG) monitoring. Anaesthesia was induced with etomidate $\left(0.7 \mathrm{mg} \mathrm{kg}^{-1}\right.$; EtomidatLipuro; Braun, Switzerland) and S-ketamine (2 $\mathrm{mg} \mathrm{kg}^{-1}$; Keta-S; Graueb AG, Switzerland) IV. The trachea was intubated with a cuffed endotracheal tube and connected to a rebreathing system. Anaesthesia was maintained with sevoflurane (Sustane Sevoflurane; Piramal Critical Care, PA, USA) in oxygen and constant rate infusions (CRI) of
S-ketamine (10 mcg kg ${ }^{-1}$ minute $^{-1}$ ) and fentanyl ( $5 \mathrm{mcg} \mathrm{kg}^{-1}$ hour $^{-1}$ ). Normocapnia was maintained with controlled mechanical ventilation. The cat became hypotensive and was unresponsive to both a fluid bolus and a dobutamine CRI; therefore, a phenylephrine CRI (Neo-Synephrine; Hospira, Australia) was started and titrated to a mean arterial pressure of $60 \mathrm{mmHg}$.

Catheterization of the left carotid artery for angiography confirmed the diagnosis. This catheter was then used for continuous invasive blood pressure measurement. The left jugular vein was prepared for catheterization and intracardiac pressure measurement. While trying to advance a 4 French multipurpose catheter into the RV and PA, the sinus rhythm changed to an idioventricular rhythm. As the cat was haemodynamically stable, the procedure was continued. Suddenly, the ECG rhythm changed into VF with loss of the pulse wave from the arterial line and loss of end-tidal carbon dioxide. The intracardiac catheter was immediately removed, sevoflurane stopped, and the cat was manually ventilated. A precordial thump was applied followed by transthoracic cardiac massage. As no change in rhythm was seen, a bolus of esmolol $\left(0.1 \mathrm{mg} \mathrm{kg}^{-1}\right.$; Esmolol OrPha; Orpha Swiss GmbH, Switzerland) was administered and within seconds, there was a conversion into sinus rhythm followed by return of circulation. No further attempts at cardiac catheterization were made, but surgical ligation of the PDA was pursued.

The recommended treatment for VF is immediate bystander cardiopulmonary resuscitation and early electrical defibrillation, followed by administration of vasoactive drugs such as epinephrine (Fletcher et al. 2012). Epinephrine primarily improves coronary and peripheral flow and pressure, but activation of the beta-1 and 2 receptors may cause deleterious effects to the myocardium (Lee et al. 2016). There are reports of the successful use of the precordial thump in people if cardiac arrest is witnessed (Pellis \& Kohl 2010) and of spontaneous cardioversion in humans with cardiac massage only (Wetherill \& Nixon 1962). In this cat, neither the thump nor initiation of cardiac massage converted the VF to a sinus rhythm. While preparing for external defibrillation, it was decided to attempt a bolus of esmolol while continuing external cardiac 
compressions. Studies in animal models have shown that beta-blockade can reduce the number of shocks necessary for defibrillation, diminish cardiac ischemia by lowering myocardial oxygen requirements, improve post-resuscitation myocardial function, reduce recurrences of arrhythmias and prolong survival (Oliveira et al. 2012). Esmolol is an ultra-short acting beta 1-adrenergic receptor antagonist that is likely to suppress epinephrinemediated hyperphosphorylation of the ryanodine receptor 2 , inhibiting excessive myocardial calcium influx and blocking epinephrine's effect on the electrical restitution, thus making the myocardium electrically stable (Oliveira et al. 2012). In humans, conversion from VF with esmolol has been reported in cases refractory to standard treatment (repeated defibrillations, epinephrine and amiodarone) (Lee et al. 2016). In the cat we report, VF was abolished after a bolus of esmolol as a first-line treatment, and a quick return of stable circulation was witnessed. Unfortunately, the cat subsequently died because of massive bleeding during surgical ligation of the PDA.

Even though we cannot prove that esmolol was the definitive reason for cardioversion, current evidence in humans suggests that esmolol could be considered for treatment of $\mathrm{VF}$, especially if electrical defibrillation is not immediately possible.

\section{Conflict of interest statement}

Authors declare no conflict of interest.
Carolina Meira ${ }^{a}$, Tony Glaus $^{b}$ \& Simone K Ringer ${ }^{a}$

${ }^{a}$ Department of Clinical Diagnostics and Services, Section Anesthesiology, Vetsuisse Faculty, University of Zurich, Zurich, Switzerland

${ }^{\mathrm{b}}$ Small Animal Department, Clinic for Small Animal Medicine, Section Cardiology, Vetsuisse Faculty, University of Zurich, Zurich, Switzerland E-mail: cmeira@vetclinics.uzh.ch (C Meira)

\section{References}

Fletcher DJ, Boller M, Brainard BM et al. (2012) RECOVER evidence and knowledge gap analysis on veterinary CPR. Part 7: Clinical guidelines. J Vet Emerg Crit Care 22, 102-131.

Lee YW, Lee KJ, Min YH et al. (2016) Refractory ventricular fibrillation treated with esmolol. Resuscitation 107, 150-155.

Oliveira FC, Feitosa-Filho GS, Ritt LE (2012) Use of betablockers for the treatment of cardiac arrest due to ventricular fibrillation/pulseless ventricular tachycardia: a systematic review. Resuscitation 83, 674-683.

Pellis T, Kohl P (2010) Extracorporeal cardiac mechanical stimulation: precordial thump and precordial percussion. Br Med Bull 93, 161-177.

Wetherill JH, Nixon PG (1962) Spontaneous cessation of ventricular fibrillation during external cardiac massage. Lancet 279, 993-994.

Received 22 January 2018; Received 15 March 2018; accepted 27 March 2018.

Available online $\mathrm{xxx}$

https://doi.org/10.1016/j.vaa.2018.03.014 